\title{
"SONHO MEU, SONHO MEU:" SENTIDOS SUBJETIVOS RELACIONADOS ÀS DIMENSÕES DA AÇÃO EMPREENDEDORA
}

\author{
"MY DREAM, MY DREAM:" SUBJECTIVE \\ SENSES RELATED TO THE DIMENSIONS OF \\ ENTREPRENEURIAL ACTION
}

\section{RESUMO}

O artigo tem como objetivo compreender os sentidos subjetivos relacionados às dimensões da ação empreendedora. A metodologia seguiu os parâmetros da Epistemologia Qualitativa de Gonzáles Rey em que é utilizado um conjunto de procedimentos específicos desenhados especialmente para desvendar os indicadores de sentido que, por sua vez, formam a configuração subjetiva. Como técnica de coleta de dados, utilizou-se a história de vida com quatro empreendedoras de micro e pequenas empresas do setor têxtil. As interpretações evidenciam sentidos subjetivos, influenciados pela história de vida, relevantes em cada uma das participantes perante o sonho de ter o próprio, associados, entre outros, à visão ideológica, ao núcleo familiar, à autoestima, à independência, à necessidade financeira, à família e a trabalhar com o que gosta. Os sentidos subjetivos são influenciados por questões individuais conscientes e inconscientes, como também por relações e imposições coletivas, advindas do meio social onde se desenvolvem os indivíduos.

Daniela Siqueira Colet danicolet@hotmail.com Mestre em Administração pela Universidade de Passo Fundo (UPF). Consultora Técnica na Universidade de Passo Fundo (UPF). Passo Fundo-RS - BR.

\footnotetext{
Anelise Rebelato Mozzato anerebe@upf.br

Doutora em Administração pela Universidade do Vale do Rio dos Sinos (UNISINOS). Professora Titular na Universidade de Passo Fundo (UPF). Passo Fundo - RS - BR.
}

Palavras-chave: Empreendedorismo Feminino. Ação Empreendedora. Sentidos Subjetivos.

\begin{abstract}
The article aims to understand the subjective senses related to the dimensions of entrepreneurial action. The methodology followed the parameters of Gonzáles Rey's Qualitative Epistemology in which a set of specific procedures is used specially designed to unveil the sense indicators that, in turn, form the subjective configuration. As a data collection technique, the life story of four female entrepreneurs from micro and small companies in the textile sector was used. The interpretations show subjective meanings, influenced by the life history, relevant in each one of the parti-
\end{abstract}


cipants before the dream of having their own, associated, among others, to the ideological vision, the family nucleus, self-esteem, independence, financial need, family and working with what they like. The subjective senses are influenced by conscious and unconscious individual issues, as well as by relationships and collective impositions, arising from the social environment where individuals develop.

Keywords: Female Entrepreneurship. Entrepreneurial Action. Subjective Senses.

\section{INTRODUÇÃO}

A temática empreendedorismo conquistou espaço nos últimos anos, tanto no meio acadêmico, como nas discussões econômicas, nos quais passou a ser considerada como relevante na formulação de políticas governamentais voltadas para o desenvolvimento dos países (SILVA; GOMES; CORREIA, 2009). Outrossim, a ação empreendedora como o agente responsável por ela, o empreendedor, são fundamentais para o crescimento econômico, o desenvolvimento local e para a geração de riqueza e empregos em uma sociedade (BARROS; FIÚSA; IPIRANGA, 2005; SILVA; GOMES; CORREIA, 2009).

O empreendedor(a) pode ser definido como uma pessoa criativa, que identifica oportunidades de negócios, que cria e define contextos, visualiza situações marcadas pela capacidade de estabelecer e atingir objetivos e concebe estruturas organizacionais que põem em funcionamento no sentido de detectar oportunidades de negócio (FILION, 1999; DOLABELA, 2002). As principais características do empreendedor para autores como McClelland (1972) e Dolabela (2002) consistem na persistência, a persuasão, a rede de contatos, a independência, a perseverança e a tenacidade.

Em pesquisa elaborada pelo Global Entrepreneurship Monitor (GEM-2019), realizada no Brasil pelo Sebrae e pelo Instituto Brasileiro de Qualidade e Produtividade (IBQP), a taxa de empreendedorismo total no Brasil foi de $38,7 \%$, sendo a segunda mais alta da série his- tórica. Ainda, estima-se que haja 53,5 milhões de brasileiros (18-64 anos) à frente de alguma atividade empreendedora.

A estimativa do número de mulheres empreendedoras no Brasil em 2019 foi de 26 milhões, muito próxima dos 29 milhões de homens (GEM, 2019). Dados da última Pesquisa Nacional por Amostra de Domicílios Contínua (PNADC), realizada pelo IBGE, mostram que cerca de 9,3 milhões de mulheres estão à frente de negócios no Brasil e que, em 2018, elas já eram 34\% dos "donos de negócio". Ainda, o Relatório Especial de Empreendedorismo Feminino (2019) no Brasil, divulgado pelo Sebrae no ano de 2019, aponta que $48 \%$ dos MEIs (Microempreendedores Individuais) são mulheres.

Para Silva et al. (2019), os motivos que fazem que as mulheres criem seu próprio negócio é a identificação de oportunidades, a expectativa de independência, a estabilidade financeira, a realização pessoal e a paixão pelo que faz. Para outras, envolvem motivos comoo desemprego, o complemento de renda, a insatisfação com o trabalho e o desejo de manter o equilíbrio entre a família e o trabalho. Nessa conjuntura, Lopes e Lima (2019) listam temas promissores citados por especialistas para o desenvolvimento dos estudos do empreendedorismo e, entre eles, Landström e Harirchi (2018) recomendam os estudos sobre gênero.

Diante do contexto apresentado, este artigo tem como objetivo compreender os sentidos subjetivos relacionados às dimensões da ação empreendedora. Justifica-se este estudo tendo em vista que o empreendedorismo feminino vem ganhando seu espaço na sociedade e, como sugerem Silva et al. (2019), é importante instigar pesquisadores a conhecer e aprofundar estudos em outras realidades e localidades no Brasil.Não obstante, no intuito de ampliar as alternativas de inteligibilidade sobre o fenômeno estudado, utilizou-se a epistemologia qualitativa desenvolvida por Gonzáles Rey (2003, 2005). Nesse sentido, a inteligibilidade da subjetividade das empreendedoras tem seu ponto de partida no empírico, não se limitando na descrição das práticas dessas mulheres, mas, sim, buscando a 
compreensão da constituição da subjetividade em seu processo histórico e social.

Após essa introdução, o artigo contempla a abordagem teórica, tratando, em um primeiro momento, do empreendedorismo, prosseguindo-se para o empreendedorismo feminino. $\mathrm{Na}$ seção seguinte, apresentam-se os procedimentos metodológicos que orientaram os caminhos seguidos para arealização da pesquisa. $\mathrm{Na}$ sequência, os dados são analisados e interpretados. Por fim, apresentam-se as considerações finais desta pesquisa.

\section{REFERENCIAL TEÓRICO}

\subsection{O EMPREENDEDORISMO}

Como referem Lopes e Lima (2019), há distintos entendimentos para o termo empreendedorismo. A palavra empreendedorismo deriva do francês "entre" e "prende", que tem como significado "estar no mercado entre o fornecedor e o consumidor" (SARKAR, 2008, p. 21). A teoria sobre o empreendedorismo tem pouco mais de trinta anos. Suas raízes são,majoritariamente, americanas e adotam uma abordagem proveniente em grande parte da teoria econômica clássica, considerando os empreendedores como puramente racionais, investigando, unicamente, seu lucro e evoluindo sobre mercados de concorrência perfeita (JULIEN; MARCHESNAY; MACHADO, 2010).

Nos meios acadêmicos, o empreendedorismo emergiu com maior intensidade nos últimos vinte anos (PELOGIO et al., 2013; LANDSTRÖM; HARIRCHI, 2018), mas o termo já era usado desde a Idade Média para descrever tanto um ator quanto uma pessoa que gerenciava grandes projetos (HISRICH; PETERS, 2002); portanto, o termo é antigo, mesmo que não debatido (LANDSTRÖM; HARIRCHI; ASTRÖM, 2012). Ao analisar o surgimento do empreendedorismo sob um contexto histórico, Greatti (2005) explicita que o empreendedorismo vem sendo estudado desde o século XII, mas ganhou maior importância a partir do século XVIII, com os conceitos de
Cantillon, Say e Schumpeter, que associaram o empreendedor à inovação e às forças direcionadoras do desenvolvimento econômico. Nesse sentido, somente a partir da evolução dos mercados econômicos os cientistas se interessaram pelo empreendedorismo e começaram a discutir o assunto (LANDSTRÖM; HARIRCHI; ASTRÖM, 2012).

A temática empreendedorismo cresceu e espalhou-se por quase todas as ciências humanas e gerenciais nos anos de1980 (FILION, 1999). Desde então, o empreendedorismo é um dos temas mais pesquisados por estudiosos de diferentes áreas, e, apesar da diversidade e da variedade de estudos, uma grande dificuldade encontrada ao se investigar o tema é o estabelecimento de uma definição única, consensual e aceita em qualquer lugar, pois o ato de empreender assume inúmeros significados ao redor do mundo e reforça a necessidade depesquisas sistemáticas direcionadas a uma melhor compreensão do fenômeno (RIMOLI et al., 2004; LANDSTRÖM; BENNER, 2010; LANDSTRÖM; HARIRCHI; ASTRÖM, 2012; LOPES; LIMA, 2019).

Filion (1999) identifica duas correntes de pensamento que definem o conceito de empreendedorismo, a partir de diferentes premissas. A primeira corrente surgiu com os economistas Richard Cantillon, Jean BaptistSay e Joseph Schumpeter que associam o empreendedorismo à inovação. A segunda corrente, desenvolvida com os comportamentalistas David McClelland, concentram-se no empreendedor, em suas características, intuição e criatividade. O autor destaca que Say é o pai do empreendedorismo, pois foi o primeiro a lançar os alicerces desse campo de estudo, mas foi Schumpeter que realmente lançou o campo do empreendedorismo, associando-o à inovação, e demonstrou também sua importância para o desenvolvimento econômico. Por outro lado, McClelland associou a ciência do comportamento ao empreendedorismo, e depois de seu trabalho, os comportamentalistas dominaram o campo empreendedorismo até o início dos anosde 1980 (FILION, 1999). A figura 1 apresenta as 
correntes que definem o conceito de empreendedorismo, segundo as ideias de Filion (1999).

Figura 1 - Correntes do empreendedorismo

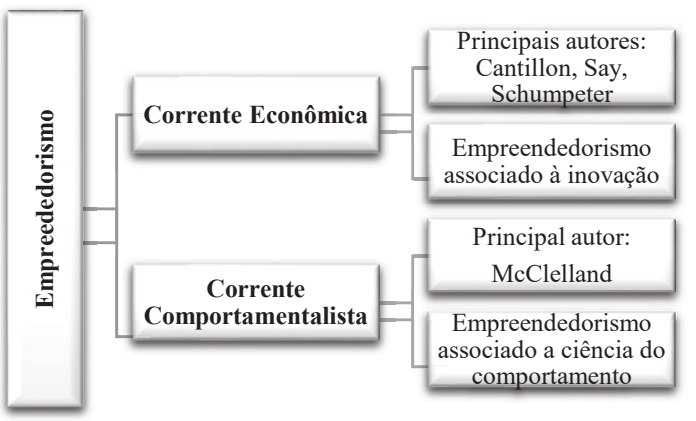

Fonte: elaborado pelas autoras.

O tema empreendedorismo, na visão de Silva, Gomes e Correia, (2009) também conquistou espaço nas discussões econômicas, em que passou a ser considerado de importância relevante na formulação de políticas governamentais voltadas para o desenvolvimento dos países. Nessa perspectiva, Pelogio et al. (2013) apontam que autores como Schumpeter (1982), Gartner (1988), Filion (1999) e Hisrich e Peters (2002), entre outros pesquisadores, destacam a importância do empreendedorismo para o desenvolvimento econômico. Para os autores, na década de 1990, o tema recebeu maior importância no Brasil, por meio da abertura da economia ao comércio internacional, que fez que micro e pequenas empresas crescessem de uma forma mais dinâmica, não só país, mas também em todo o mundo.

Para compreender o fenômeno do empreendedorismo, deve-se considerar o indivíduo empreendedor, o projeto, o meio ambiente e, também, as conexões entre eles ao longo do tempo (BRUYAT; JULIEN, 2001). Os empreendedores possuem características específicas que os diferenciam dos demais, como perseverança e tenacidade, utilizando o fracasso como fonte de aprendizado e desenvolvem forte intuição como resultado de um profundo conhecimento do ramo em que atuam (FILION, 1999). Por outro lado, McClelland (1972) destaca o aspecto motivacional como orientador da ação empreendedora, e a motivação do trabalhador estão relacionados à necessidade de realização, de afiliação e de poder.

Degen (2009, p. 8) afirma que o "empreendedor é aquele que tem visão do negócio e não mede esforços para realizar o empreendimento. A sua realização é ver sua ideia concretizada em seu negócio." Em sentido semelhante, Shane e Venkataraman (2000) explicitam que a exploração deuma oportunidade empreendedora depende de que oempreendedor acredite na possibilidade de lucro, superando o custo da oportunidade e o investimento de capital. Dessa forma, entende-se que as pessoas empreendedoras estão sempre prontas para agir, desde que existam, no meio em que atuam, condições propícias e apoio (TEIXEIRA et al., 2011).

Landström e Benner (2010) apresentam a evolução cronológica do empreendedorismo, criando uma conjuntura de três eras distintas do pensamento empreendedor, diante das opiniões que dominavam a época, conforme é apresentado na figura 2.

Figura 2- Eras do Pensamento Empreendedor

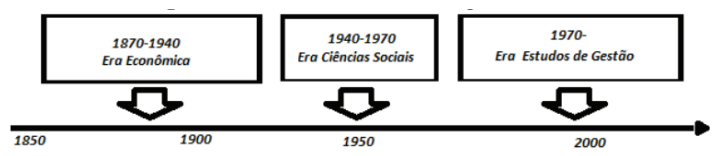

Fonte: (LANDSTRÖM; BENNER, 2010, p. 20).

Como é apresentado por Landström e Benner (2010) e reforçado por pesquisas mais contemporâneas, o empreendedorismo é estudado sob a visão dos estudos de gestão. Tais estudos, sob diferentes perspectivas, salientam os aspectos afetivos que envolvem o empreendedor. Como pontuam Nassif, Ghobril e Silva (2010), embora os aspectos cognitivos e afetivos, muitas vezes, sejam tratados separadamente na teoria, eles não ocorrem separados na prática. Inclusive, os autores referem que os empreendedores iniciam seus empreendimentos mais influenciados por aspectos afetivos do que cognitivos, a exemplo do saber e gostar de fazer algo específico. Ou seja, inicialmente, a tomada de decisão é mais intuitiva do que analítica (CAMPOS et al., 2015). Entretanto, refe- 
rem Nassif, Ghobril e Sival (2010) que, na medida em que os empreendimentos crescem, os aspectos cognitivos influenciam mais as ações dos empreendedores. Enfim, em todas as fases do empreendedorismo,o afeto é, notadamente, relevante à cognição e vice-versa (GARCÍA; PUENTE; MAZAGATOS, 2015).

O empreender como opção de carreira (DEGEN, 2009) é ou torna-se uma opção de trabalho, independentemente do gênero. Entretanto, entre os diferentes tipos depesquisas sobre o empreendedorismo (social, criativo, educacional), tem-se o empreendedorismo feminino. Entende-se que o empreendedorismo feminino segue a mesma lógica, mas com suas peculiaridades. Portanto, no tópico seguinte, discorre-se sobre o empreendedorismo feminino e suas especificidades; entretanto, sem a pretensão de fazer distinção de gênero, visto que as características empreendedoraspodem ser encontradas tanto em homens quanto em mulheres. Inclusive, Cortez, Araújo e Pereira (2017) confirmam a relevância da proposição de Nassif, Ghobril e Silva (2010) quanto aos aspectos afetivos e cognitivos que influenciam nas diferentes fases do empreendedorismo feminino.

\subsection{EMPREENDEDORISMO FEMININO}

Os diversos conceitos de empreendedorismo existentes não fazem distinção de gênero, ainda que algumas definições contemplassem, quase exclusivamente, o público masculino em razão da época. No entanto, as mulheres escrevem, atualmente, um novo capítulo na história do empreendedorismo. Gomes, Santana e Araújo (2009) destacam que uma das principais razões para que a mulher venha a ter o próprio negócio é a flexibilidade de horários, pois, dessa forma, pode compatibilizar o trabalho e a família. Já para Strobino e Teixeira (2014), são raras as empreendedoras que têm a fronteira entre o trabalho e a vida pessoal, ou a vida em família bem definida, e, como consequência, geralmente o conflito trabalho-família é defrontado. Machado (2013) também relata a experiência de mulheres que apresentam como desafio a busca do equilíbrio entre família e trabalho.

Adicionalmente, Lindo et al. (2007) inferem que a flexibilidade de horário para todas as empresárias não implica menos horas trabalhadas, mas em liberdade de administrar o tempo de modo que consigam dar prioridade à harmonia familiar ou ao cuidado a si próprias, preservando uma boa qualidade de vida.Acerca dos atributos pessoais, o trabalho de Martins et al. (2010) aponta como características comuns a empreendedoras: a determinação paraperseguir objetivos, alcançar metas e superar dificuldades; o perfil inovador; o foco na construção do futuro; e a autonomia. A pesquisa também mostra que as empreendedoras têm uma clara tendência à organização e à extroversão, autoconfiança e bom autocontrole, abertura para o diálogo e capacidade de administrar conflitos.

A pesquisa de Cortez, Araújo e Pereira (2017) identificou que, na fase de nascimento dos negócios, as empreendedoras agiam influenciadas por aspectos afetivos, tais como independência, paixão pelo empreendimento e vontade de fazer o que gosta. Nas fases seguintes, quando há a percepção da necessidade de uma melhor organização, o planejamento, o estabelecimento de metas e a formação de parcerias passam a ser buscados. Entretanto, aspectos como perseverança, iniciativa, coragem e realização por fazer o que gosta permanecem influenciando suas ações, trazendo a conclusão de que a influência dos aspectos cognitivos ascende, todavia juntamente com a influência dos aspectos afetivos. Na mesma lógica já pensada por Nassif, Ghobril e Silva (2010) e García, Puente e Mazagatos (2015), sem fazer a distinção de gênero.

Os motivos apontados sobre as mulheres empreenderem consistem no desejo de realização e independência, percepção de oportunidade de mercado, dificuldades em ascender na carreira profissional em outras empresas, necessidade de sobrevivência e como maneira de conciliar trabalho e família (MACHADO et al., 2003), além do fato de muitas empreendedoras 
pertencerem a famílias de empreendedores, o que as direciona, automaticamente, ao empreendedorismo, como se fosse uma predisposição genética. Ou seja, há uma vinculação entre a motivação e a sobrevivência dessas empreendedoras, como pontuam Rey-Martí, Porcar e Mas-Tur (2015). Nessa lógica, Kobeissi (2010) salienta a importância do empreendedorismo feminino para o crescimento econômico e a redução da pobreza.

Silva et al. (2019) destacam alguns fatores que afetam o empreendedorismo feminino,como o preconceito, a discriminação, a falta de acesso a recursos financeiros e, muitas vezes, o conflito entre trabalho e família, especialmente quando essas mulheres possuem filhos ainda pequenos. Comumente, devido à necessidade de sobrevivência do empreendimento, muitas empreendedoras dedicam-se ao trabalho, sem, muitas vezes, conseguir separar a vida privada da laboral.

A pesquisa desenvolvida por Machado, Guedes e Gazola (2017), junto a mulheres empreendedoras, revelou que o crescimento dos empreendimentos encontra-se relacionado à quantidade de horas dedicadas ao trabalho, além do conhecimento prévio, a criatividade e a capacidade de inovação. Outro aspecto refere-se à figura do marido, pois também exerce um papel crucial na vida das mulheres empreendedoras, sendo uma fonte de apoio emocional de destaque no fortalecimento do ato de empreender, fonte de recursos e conselheiro na tomada de decisão como inferem Alperstedt, Ferreira e Serafim (2014).

Concomitantemente, compreende-se que a mulher empreendedora precisa ser analisada por meio da concepção sócio-histórica, embora ela seja um indivíduo singular, mas que faz parte de um contexto histórico. Assim, a mulher é capaz de influenciar e ser influenciada por esse contexto. Portanto, tanto a subjetividade individual como a social fazem parte, constituindo significados e significantes. Como registram Ferreira e Nogueira (2013, p. 403), "tanto o ser mulher quanto o ser empreendedorafuncionam como produções sociais, configuradas por meio dos significados atribuídos pelo próprio indiví- duo, que lhes confere sentido único." Portanto, dada a importância da subjetividade no empreendedorismo feminino, ela é trabalhada na sequência com base em González Rey.

\subsection{A SUBJETIVIDADE DE GONZÁLEZ REY}

Segundo González Rey (2003, 2005), o sentido subjetivo é elaborado por meio de uma definição de sentido por sua relação inseparável com a subjetividade que representa uma unidade integradora de elementos diferentes, processos simbólicos e emoções, sendo a integração desses elementos que define o sentido subjetivo. O autor evidencia que os sentidos subjetivos aparecem de forma indireta na qualidade da informação,que pode ser identificada no lugar em que uma palavra se encontra emuma frase ou em uma narrativa; na comparação de significações distintas que podem ser observadas em uma expressão, no nível diferenciado detratamento de temas, ou seja, não aparece diretamente da expressão intencional do indivíduo ou em uma frase ou palavra.

Complementarmente, Gonçalvez Rey (2003) entende que o sentido subjetivo não acontece apenas na subjetividade individual, mas, sim, associado ao conceito de subjetividade social. Dessa forma, o autor infere a importância das práticas sociais, ou seja, essa teoria considera que a subjetividade se desenvolve em um contexto sócio-histórico e é influenciada por questões de ordem consciente e inconsciente, sendo socialmente construída e historicamente situada. O sujeito, portanto, deve ser compreendido em sua complexidade de práticas sociais (GONZÁLEZ REY, 2003, 2005). Portanto, ao trabalhar subjetividade, o autor entende que a mente não se separa da história, da cultura e da vida social do sujeito.

Nesse sentido, para González Rey (2012, p. 137), "a subjetividade é um macroconceito que integra os complexos processos e formas de organização psíquicos, envolvidos na produção de sentidos subjetivos." Ao trabalhar o seu conceito de subjetividade, o autor entende que 
a mente não se separa da história, da cultura e da vida social do sujeito. Desse modo, a emoção transforma-se com os registros simbólicos, fazendo que o sujeito não somente se adapte ao contexto no qual está inserido, mas também elabore sobre o mundo em que vive. Assim, considera-se a epistemologia de González Rey como uma das alternativas para a construção de estudos transdisciplinares.

Por fim, para o autor, a pluralidadeem termos qualitativos dos processos subjetivos e a imensa complexidade dos processos envolvidos em sua composição não podem ser entendidas por meio das respostas simples dos participantes da pesquisa que emergem do uso de instrumentos padronizados. Para estudar a subjetividade, implica inserir-se nos modos profundamente complexos de manifestação do sujeito e progredir na elaboração do conhecimento por caminhos que não são lineares e tampouco explícitos González Rey (2012).

\section{PROCEDIMENTOS METODOLÓGICOS}

A pesquisa qualitativa se baseia na epistemologia qualitativa de González Rey (2005). A teoria da subjetividade do pesquisador entende que o novo modelo de ciência que valoriza o singular na pesquisa está intimamente ligado a uma opção epistemológica em que as pesquisas possuem validade científica, não pela generalização estatística, mas pela capacidade de gerar conhecimento a partir do singular. A análise recai sobre os processos explicando os objetivos em vez de descrevê-los.

Nesse sentido, a inteligibilidade da subjetividade das empreendedoras tem seu ponto de partida no empírico, mas não se esgota na descrição das práticas dessas mulheres. Além disso, é necessário buscar a compreensão da constituição da subjetividade em seu processo histórico e simbólico. No sentido salientado por González Rey (2009), tanto a subjetividade individual como a social necessitam ser desvelados.

As participantes da pesquisa são quatro empreendedoras de micro e pequenas empresas do setor têxtil, localizadas no noroeste do Rio Grande do Sul. A escolha das depoentes deu-se aleatoriamente e por acessibilidade. Os nomes das participantes foram alterados para resguardar suas identidades, sendo nomeadas como flores: Rosa, Margarida, Hortência e Dália.

Ponderando a subjetividade e as histórias experiência das por cada empresária, González Rey (2005) recomenda ao pesquisador que, na fase de coleta de dados, estabeleça um cenário em que os participantes possam se sentir à vontade para falar. Assim, com tais considerações, foram agendados horários para a realização da coleta de dados por meio da técnica história de vida (GODOY, 2018; MOZZATO; COLET; GRZYBOVSKI, 2018). Tal coleta de dados ocorreu no primeiro semestre de 2018, quando estas foram gravadas e, no momento,notas de campo foram efetivadas.

Assim, seguindo a concepção de Rey (2003), as análises ocorreram por meio da captação e interpretação das expressões dos sujeitos da pesquisa. Portanto, tanto as notas de campo como a transcrição das entrevistas foram fundamentais em razão da apreensão dos sentidos subjetivos presentes. Sendo assim, o processo de construção não se orientou por concepções preconcebidas, e, sim, por meio do processo analítico reflexivo dos pesquisadores, os quais foram construindo a teoria norteadora da pesquisa. Nessa lógica, os resultados são apresentados e discutidos na sequência, sendo que, em um primeiro momento, algumas características das empreendedoras são apresentadas.

\section{APRESENTAÇÃO E DISCUSSÃO DOS RESULTADOS}

\subsection{CONHECENDO AS EMPREENDEDORAS}

Como ponto de partida para a apresentação e a análise dos resultados, apresentam-se as participantes desta pesquisa que foram nomeadas com nomes de flores, conforme são apresentadas no quadro 1. 
Quadro 1 - Perfil das participantes

\begin{tabular}{|c|c|c|c|}
\hline Nome & Idade (anos) & Escolaridade & Tempo de empresa em anos \\
\hline Rosa & 25 & Superior Completo & 1,4 \\
\hline Margarida & 41 & Ensino Médio & 22 \\
\hline Hortência & 38 & Ensino Médio & 24 \\
\hline Dália & 44 & Superior Completo & 18 \\
\hline
\end{tabular}

Fonte: dados da pesquisa.

Analisando o quadro 1, observa-se que há diversidade de faixa etária, e a empresária mais jovem tem 25 anos e a mais velha tem 44 anos. No que se refere ao tempo de empresa, percebe-se que a empresa mais jovem tem 1,4 anos e a mais antiga tem 24 anos de existência. As histórias de vida contadas pelas empreendedoras relatam como elas iniciaram as suas empresas, as motivações para tal, os apoios e as dificuldades vivenciadas, as quais são apresentadas e interpretadas a seguir, evidenciando o caminho percorrido para a realização dos sonhos, como o fragmento da história de Rosa que é descrito a seguir.

\subsection{ROSA: "MAS SEMPRE COM AQUELA VONTADE DE TER UM NEGÓCIO"}

Durante a infância de Rosa, ela sempre escutou a sua mãe falar que queria ter um negócio próprio. A sua mãe havia trabalhado como vendedora, masnunca gostou dos sistemas das empresas, da forma como as empresas eram administradas. Sua mãe falava que, se ela tivesse um negócio, seria totalmente diferente, que ela faria da forma dela. Então, desde pequena, Rosa escutava isso da mãe, mas nunca tiveram a oportunidade de elas terem seu próprio negócio.

Rosa fez pedagogia e estava trabalhando na sua área, quando conheceu seu esposo Fabrício,e a vontade de ter seu próprio negócio falou ainda mais alto. Fabrício tinha seu próprio negócio há mais de 16 anos, e esse foi um dos fatores que influenciou muito, uma vez que ele dizia que ela deveria ter seu próprio negócio, que ela tinha potencial e capacidade. Ele sempre apostou muito em Rosa e em sua sogra para terem um negócio, independentemente do que fosse.

O negócio apareceu quando a tia de Rosa trabalhava em uma empresa de uniformes e comentou com a proprietária que elas queriam abrir um negócio. Dessa forma, a proprietária da empresa ligou para Rosa, oferecendo a empresa, e ela e sua mãe acabaram comprando. Nas palavras de Rosa: "A primeira coisa para ser empreendedora é ter coragem, é não ter medo, é encarar a dificuldade, porque não adianta tu ter lá na tua conta um capital enorme se tu não saber empreender, se tu não souber administrar o negócio".

Por meio da história de vida da Rosa, é possível identificar a subjetividade nas relações familiares, a socialização da infância que exerceu influência no ato de empreender, indicando processos simbólicos e emoções. Também, a coragem de empreender em uma área de atuação diferente da sua formação (pedagogia), aprendendo muitas coisas na prática do setor têxtil. A configuração subjetiva dessa mulher fica manifestada em sua fala que, para empreender, é necessário ter coragem, não ter medo e encarar a dificuldade. Com a representação social do que é um indivíduo empreendedor, ela constrói a sua própria identidade e suas ações são realizadas de forma a corroborar essa característica.

O fragmento dessa história vai ao encontro do que Cortez, Araújo e Pereira (2017) destacam sobre asas mulheres empreendedoras. Sem fazer distinção de gênero, também Nassif, Ghobril e Silva (2010), Landström e Benner (2010) e García, Puente e Mazagatos (2015) salientam os aspectos afetivos envolvidos no empreendedorismo.Ainda, Rosa evidencia a figura do marido que foi uma fonte de apoio emocional de destaque no fortalecimento do 
ato de empreender (ALPERSTEDT; FERREIRA; SERAFIM, 2014). Ou seja, além dos aspectos subjetivos envolvidos, a empreendedora ainda tinha ascondições propícias e o apoio salientado por Teixeira et al. (2011).

\subsection{MARGARIDA: "QUERIA TER MEU PRÓPRIO NEGÓCIO E TER A MINHA INDEPENDÊNCIA"}

Margarida começou a trabalhar aos 14 anos em uma empresa de confecção como costureira onde trabalhou sete anos e resolveu trabalhar em casa como terceirização pra própria empresa. A empresária relata que gostava muito de moda e, em parceria com outra colega, resolveram abrir uma empresa no ramo infantil, e, após um ano, a empresária comprou a parte da sócia, porque queria ter seu próprio negócio e ter sua independência. Segundo a empreendedora:

Foi um grande desafio, tive que me especializar em modelagem e criação, te digo foi uma vitória, pois os antigos sócios acharam que nós não ia conseguir levar a marca em frente. Mas a minha garra e do meu marido me fez eu procurar novidades e aí vimos que era a moda feminina que era nosso sonho. Temos muito chão pela frente, mas tenho um grande homem e junto trabalhamos pra fazer outras famílias ter o seu ganho no final do mês. Não é fácil nesse país, nesses últimos anos tivemos que ser firme pra não desisti.

A história de vida relatada pela Margarida revela a sua trajetória, a qual começou cedo no trabalho e demonstrou contínua perseverança, garra e coragem para ter seu próprio negócio e realizar seu sonho. Além disso, ficam implícitas as dificuldades vivenciadas e a força de vontade da empresária em seguir em frente. O relato de Margarida é semelhante ao de Rosa no que se refere ao apoio do seu esposo, na lógica da afirmação de Alperstedt, Ferreira e Serafim (2014) de que o marido também exerce um papel crucial na vida das mulheres empreendedoras. A história de vida da Margarida revela a sua atuação no espaço social vivido, o qual gera formas de subjetivação, visto estar constantemente inserida nesse espaço. É possível também destacar o indicador de sentido subjetivo responsabilidade. Começar a trabalhar muito jovem, terceirizar produção e prosperar para fazer outras famílias ter o seu ganho no final do mês. A história de Margarida é imbuída de emoção.

Ainda, por mais que a emoção faça parte da trajetória da empresária em suas diferentes fases como empreendedora, também se percebe, por meio do relato, a necessidade de planejamento e estabelecimento de metas, conforme inferem Machado, ST-CYR, Mione e Alves (2003) e Cortez, Araújo e Pereira (2017) sobre as fases do empreendedorismo. Os simbolismos presentes na fala da empreendedora demonstram a vinculação entre a motivação e a sobrevivência para empreender, como analisam Rey-Martí, Porcar e Mas-Tur (2015), ou seja, entre o emocional e o cognitivo (SILVA et al., 2019). Nessa história de vida, fica evidenciada a postura epistemológica de Gonzáles Rey $(2005,2009)$, na qual o sujeito tem papel ativo, consciente, reflexo e gerativo em sua constituição enquanto tal.

\subsection{HORTÊNCIA: "EU CONTINUO POR NECESSIDADE FINANCEIRA, PORQUE A GENTE TEM QUE TRABALHAR"}

Hortência relata que morava em um lugar muito pobre na área indígena, um lugar de pessoas com bastante dificuldade, e sua mãe sempre teve preocupação de tentar ajudar os outros. Sua mãe arrumou um dinheiro emprestado com uma tia, uns sacos de soja e comprou alguns tecidos. Inicialmente, fabricavam calcinha e cueca, e Hortência, com apenas 8 anos, ajudava sua família. Com o tempo, seu irmão fez um curso de serigrafia, e eles começaram a produzir camisetas personalizadas, e foi montada uma estrutura melhor da empresa. 
Os quatro irmãos trabalhavam na empresa e, com o tempo, conseguiram clientes maiores. No entanto, o tempo foi passando e cada um seguiu direções diferentes. Contudo, Hortência precisou voltar para a cidade para ajudar seus pais e assumir os negócios por necessidade financeira, mas também, porque era o sonho do pai e da mãe, e ainda, sabia que a empresa precisava continuar.

As relações familiares aparecem a todo o momento no relato dessa empreendedora. A subjetividade de Hortência é marcada pelas relações familiares e sua história, ao mesmo tempo em que influencia na constituição subjetiva daqueles que estão à sua volta. É possível também destacar o indicador de sentido subjetivo necessidade e financeiro, pois, desde pequena, ajudou a família, assim, por questões familiares, sentiu necessidade (objetiva e subjetiva) de retornar e dar continuidade aos negócios da família.

Por meio da história de vida da Hortência e a respectiva história do empreendimento, fica notória a vinculação entre a motivação e a sobrevivência, como referem Rey-Martí, Porcar e Mas-Tur (2015) e Silva et al. (2019).Ainda, tal relato corrobora Machado, ST-CYR, Mione e Alves (2003) sobre muitas empreendedoras pertencerem a famílias de empreendedores, o que acaba, muitas vezes, direcionando-as ao empreendedorismo.

\subsection{DÁLIA: "SEMPRE GOSTEI MUITO DA ÁREA DE CONFECÇÃO”}

Dália terminou o segundo grau em 1992, fez um curso de modelagem e começou a produzir lingerie pra vender nas horas vagas, pois trabalhava em um escritório agrônomo. Em 1993, prestou um concurso público e mudou de emprego e cidade; contudo, continuou trabalhando com confecção nas horas vagas, produzindo roupas sob medida. A empresária relata que sempre gostou muito da área de confecção:

Em 1996 casei e mudei de cidade, como não tinha muita oferta de em- prego em meu município fui trabalhar na cidade vizinha numa fábrica de confecções, onde me encantei ainda mais pela moda. Um ano depois decidi trabalhar só em casa, confeccionava lingerie, roupas infantis e adultas e algumas sacoleiras vendiam pra mim. Em 2000, consegui construir minha casa própria já com espaço destinado para fábrica e loja, assim nascia a minha empresa.

A Dália, por meio da sua história de vida, revela que sempre trabalhou e gostou muito da área da confecção, inicialmente tendo essa como uma atividade secundária, trabalhando em casa. Em seu relato, aparecem indicadores subjetivos como perseverança, iniciativa, coragem e a realização por fazer o que gosta.

O gosto pelo que se faz (ramo de negócio) é expresso claramente na fala da Dália, o que a impulsionou a empreender, sendo este um dos principais motivos para tal, apontado por Cortez, Araújo e Pereira (2017). Também nessa história a influência dos aspectos afetivos é marcante, estando a paixão no centro das escolhas, o que é ressaltado por Dalabela (2002).

Ainda, a história dessa mulher empreendedora, em seus diferentes espaços sociais e históricos,também é repleta de simbolismos que revelam que o sentido subjetivo de gênero, ao mesmo tempo em que é configurado pela responsabilidade, é também motivo de orgulho quando se alcança sucesso profissional.

\subsection{ANÁLISES COMPARATIVAS DAS HISTÓRIAS DE VIDA: PREVALÊNCIA DA SUBJETIVIDADE}

Todos os elementos presentes nas históriasde vida das mulheres empreendedoras são subjetivados de maneira única. Percebe-se que o empreendedorismo faz parte de suas vidas, e ficam evidenciadas as motivações que levaram essas mulheres a empreender. $\mathrm{O}$ sonho de ter um negócio, a independência, a necessidade financeira, trabalhar com o que gosta, e, ainda, 
o apoio dos companheiros foram muito importantes e motivadores para algumas mulheres empreenderem. Tais motivos vão ao encontro dos citados por Silva et al. (2019).

Vale mencionar que, em todos os depoimentos, a emoção prevaleceu. Cada trajetória confere um caráter totalmente singular, bem como o orgulho de poder contar suas histórias. Cada empreendedora em seus diferentes espaços sociais (empreendimentos e famílias) geram formas de subjetivação, não sendo possível separar o sujeito do social, no sentido expresso por Gonzáles Rey (2003, 2005, 2009). Suas histórias pessoais estão imbricadas em suas histórias profissionais, uma "afetando" a outra, estando a emoção presente constantemente, a qual não pode ser desconsiderada nos estudos sobre empreendedorismo.

A psique de cada empreendedora é manifestada por meio de suas histórias experiência das, as quais demonstram características próprias do empreendedorismo, sobretudo do empreendedorismo feminino. O sentido subjetivo de cada empreendedora é único, o que é visível no caráter singular da história de cada uma. Por mais que pareça redundante, cabe destacar que não há razões, facilidades ou dificuldades universais para o empreendedorismo, mas sim, cada empreendedora tem suas próprias características individuais, suas próprias histórias e seus próprios contextos.

\section{CONSIDERAÇÕES FINAIS}

Chegando ao final deste trabalho de pesquisa, entende-se que o objetivo inicial do artigo foi atingido, possibilitando melhor compreensão dos sentidos subjetivos relacionados às dimensões da ação empreendedora, com a utilização da metodologia da Epistemologia Qualitativa de Gonzáles Rey, possibilitando desvendar indicadores de sentido que, por sua vez, formam a configuração subjetiva do empreendedorismo feminino.

Este artigo contribui para os estudos sobre empreendedorismo feminino, sobretudo por trabalhar na teoria das configurações sub- jetivas, na qual tanto a subjetividade individual como a social são reveladas. Ainda, como contribuição metodológica desta pesquisa, a citar: a história de vida como estratégia para coleta de dados, uma vez que a sua utilização nos estudos sobre empreendedorismo é menos recorrente. Por fim, cumpre dizer que, por mais que aqui a teoria da subjetividade de González Rey (2003, $2005,2009)$ foi adotada como opção para entender a subjetividade das empreendedoras, ela é útil para análises em diversos espaços sociais, como possibilidade de estudos futuros.

Ainda como sugestões de futuros estudos, mas agora voltados para o empreendedorismo feminino especificamente, apresentam-se as empreendedoras de startups em ambientes de inovação, as empreendedoras sociais voltadas a grupos vulneráveis e o próprio empreendedorismo por mulheres em situação de vulnerabilidade.

\section{REFERÊNCIAS}

ALPERSTEDT, G. D.; FERREIRA, J. B.; SERAFIM, M. C. Empreendedorismo feminino: dificuldades relatadas em histórias de vida. Revista de Ciências da Administração, v. 16, n. 40, p. 221-234, 2014.

BARROS, F. S. O.; FIÚSA, J. L. A.; IPIRANGA, A. S. R. O empreendedorismo como estratégia emergente de gestão: histórias de sucesso. REAd, vol. 11, n. 5, set./out. 2005.

BRUYAT, C.; JULIEN, P. A. Defining the field of research in entrepreneurship. Journal of business venturing, v. 16, n. 2, p. 165-180, 2001.

CAMPOS, H. M. et al. Strategic decision making, entrepreneurial orientation and performance: an organizational life cycle approach. Revista de Administração Faces, v. 14, n. 2, p. 8-24 abr./jun. 2015.

CORTEZ, A. E. G.; ARAÚJO, A. G.; PEREIRA, F. A. M. A Influência dos Aspectos Cognitivos e Afetivos de Mulheres Empreendedoras 
nas Diferentes Fases de Desenvolvimento de um Negócio. Revista de Empreendedorismo e Gestão de Pequenas Empresas, v. 6, n. 2, p. 234-262, 2017.

DEGEN, R. J. O empreendedor: empreender como opção de carreira. São Paulo: Pearson Prentice Hall, 2009.

DOLABELA, F. O segredo de Luísa: uma ideia, uma paixão e um plano de negócios:como nasce o empreendedor e se cria uma empresa. 13. ed. São Paulo: Cultura, 2002.

FERREIRA, J. M.; NOGUEIRA, E.E.S. Mulheres e Suas Histórias: Razão, Sensibilidade e Subjetividade no Empreendedorismo Feminino. RAC, Rio de Janeiro, v. 17, n. 4, art. 1, p. 398-417, jul./ago. 2013.

FILION, L. J. Empreendedorismo: Empreendedores eproprietários-gerentes de pequenos negócios. Revista de Administração, São Paulo, v. 34, n. 2, p. 5-28, abr./jun. 1999.

GARCÍA, J. B. D.; PUENTE, E. Q.; MAZAGATOS, V. B. How Affect Relates to Entrepreneurship: A Systematic Review of the Literature and Research Agenda. International Journal of Management Reviews, v. 17, n. 2, p. 191-211, 2015.

GARTNER, W. B. Who is an entrepreneur? Is the wrong question. American Journal of Small Business, New York, v. 12, n. 4, p. 1132, 1988 .

GONZÁLEZ REY, F. L. Sujeito e subjetividade. Tradução R. S. Guzzo. São Paulo: Pioneira Thomson Learning, 2003.

GONZÁLEZ REY, F. L. Pesquisa qualitativa e subjetividade: os processos de construção da informação. Tradução M. A. Silva. São Paulo: Pioneira Thomson Learning, 2005.

GONZÁLEZ REY, F. L. O social na psicolo- gia e a psicologia no social: a emergência do sujeito. 2. ed. Tradução Joscelyne V. L. Petrópolis: Vozes, 2009.

GONZÁLEZ REY, F. A configuração subjetiva dos processos psíquicos: avançando na compreensão da aprendizagem como produção subjetiva. In: MARTINEZ, A. M.; SCOZ, B. J. L.; CASTANHO, M. I. S. (org.). Ensino e aprendizagem: a subjetividade em foco Brasília: Líber Livro, 2012. p. 21-41.

GODOY, C. K. Reflexão a respeito das contribuições e dos limites da história de vida na pesquisa em administração. ADMINISTRAÇÃO: Ensino e Pesquisa, Rio de Janeiro, v. 19, n. 1, p. 161-175, 2018.

GOMES, A. F.; SANTANA, W. G. P; ARAÚJO, U. P. "Empreendedorismo Feminino: O Estado-da-arte". In: ENCONTRO DA ANPAD, 33., 2009, São Paulo. Anais [...]. São Paulo: Anpad, 2009.

GLOBAL ENTREPRENEURSHIP MONITOR. Empreendedorismo no Brasil 2019: Relatório Executivo. [S.l.: s.n.], 2019.

HISRICH, R. D.; PETERS, M. P. Entrepreneurship.New York: McGraw Hill, 2002.

IBGE. Instituto Brasileiro de Geografia e Estatística. Empreendedorismo Feminino no Brasil. Relatório especial, 2019. Disponível em: https://www.sebrae.com.br/Sebrae/Portal $\% 20$ Sebrae/UFs/GO/Sebrae $\% 20$ de $\% 20$ A\%20a\%20Z/Empreendedorismo\%20Feminino\%20no\%20Brasil\%202019_v5.pdf. Acesso em: 7 dez. 2020.

JULIEN, P. A.; MARCHESNAY, M.; MACHADO, H. V. Interdisciplinaridade da pesquisa em empreendedorismo e em PME: por uma teoria empreendedora que contemple diferenças culturais. Revista Gestão e Planejamento, Salvador, v. 11, n. 2, p. 355-368, jul./ dez. 2010. 
KOBEISSI, N. Gender factors and female entrepreneurship: International evidence and policy implications. Journal of International Entrepreneurship, v. 8, n. 1, p. 1-35, 2010.

LANDSTRÖM, H.; HARIRCHI, G.The social structure of entrepreneurship as a scientific field.Research Policy, n. 47, v. 3, p. 650- 662, 2018. doi:10.1016/j.respol.2018.01.013

LANDSTRÖM, H.; HARIRCHI, G.; ASTRÖM, F. Entrepreneurship: Exploring the Knowledge base. Research Policy, v. 41, p. 1154-1181, 2012.

LANDSTROM, H.; BENNER, M. Entrepreneurship research: a history of scholarly migration. In: LANDSTROM, H.; LOHRKE, F. (org.). Historical foundations of entrepreneurship research. GreatBritain: Edward ElgarPublishing, 2010. p. 15-45.

LINDO, M. R. et al. "Vida Pessoal e Vida Profissional: os desafios de equilíbrio para mulheres empreendedoras no Rio de Janeiro". Revista de Administração Contemporânea Eletrônica, v. 1, p. 1-15, jan./abr. 2007.

LOPES, R. M. A.; LIMA, E. Desafios atuais e caminhos promissores para a pesquisa em empreendedorismo. RAE-Revista de Administração de Empresas, v. 59, n. 4, p. 284292, ago. 2019. doi:http://dx.doi.org/10.1590/ S0034-759020190406.

MACHADO, H. P. V. et al. O processo de criação de empresas por mulheres. Revista de Administração de Empresas, v. 2, p. 6-20, 2003.

MACHADO, H. P. V.; GUEDES, A.; GAZOLA, S. Determinantes e dificuldades de crescimento para mulheres empreendedoras. RPCA, Rio de Janeiro,v. 11, n. 1, p.85-99, jan./mar. 2017. DOI: http://dx.doi.org/10.12712/rpca. v11i1.828

MARTINS, C. B.; et al. Empreendedorismo feminino: características e perfil de gestão em pequenas e médias empresas. Revista de Administração da UFSM, v. 3, n. 2, art. 9, p. 288302, 2010.

MOZZATO, A. R.; COLET, D. S.; GRZYBOVSKI, D. O potencial da história de vida como estratégia de pesquisa qualitativa em administração: 'você pode me contar a sua história?'. Caderno de Administração (UEM), v. 26, n. 1, p. 170-186, 2018. http://dx.doi.org/10.4025/ cadadm.v26i1.41688

MCCLELLAND, D. C. A sociedade competitiva: realização e progresso social. Rio de Janeiro: Expressão e Cultura, 1972.

NASSIF, V. M. J.; GHOBRIL, A. N.; SILVA, N. S. Understanding the entrepreneurial process: a dynamic approach. Brazilian Administration Review, v. 7, n. 2, p. 213-226, 2010.

PELOGIO, E. A. et al. Empreendedorismo e estratégia sob a ótica da lógica Effectuation. Revista Ibero-Americana de Estratégia, v. 12, n. 2, p. 228-249, 2013.

REY-MARTÍ, A.; PORCAR, A. T.; MAS-TUR, A. Linkingfemaleentrepreneurs' motivationto business survival. Journalof Business Research, v. 68, n. 4 , p. 810-814, 2015.

SARKAR, S. O empreendedor inovador: faça diferente e conquiste seu espaço no mercado. Rio de Janeiro: Elsevier, 2008.

SCHUMPETER, J. A. A teoria do desenvolvimento econômico. São Paulo: Nova Cultural, 1982.

SHANE, S.; VENKATARAMAN, S.The promise of entrepreneurship as a field of research Academy of Management. The Academy of Management Review, New York, v. 25, n. 1, p. 217-226, 2000.

SILVA, M. A. O. M.; GOMES, L. F. A. M.; 
CORREIA, M. F. Cultura e Orientação Empreendedora: uma Pesquisa Comparativa entre Empreendedores em Incubadorasno Brasil e em Portugal. RAC, Curitiba, v. 13, n. 1, art. 4, p. 57-71, jan./mar. 2009.

SILVA, P. M. M. et al. A Resiliência no Empreendedorismo Feminino. Gestão e Sociedade, v. 13, n. 34, p. 2629-2649, 2019.

STROBINO, M. R. C.; TEIXEIRA, R. M. "Empreendedorismo Feminino e o Conflito Trabalho-Família: Estudo de Multicasos no Setor da Construção Civil da Cidade de Curitiba". Revista Administração, USP, São Paulo, n. 49, v. 1, p.1-18. jan./fev./mar.2014.

TEIXEIRA, R. M. et al. Empreendedorismo jovem e a influência da família: a história de vida de uma empreendedora de sucesso. REGE, São Paulo, v. 18, n. 1, p. 3-18, jan./mar. 2011. 